\title{
Supraventricular tachycardia with abrupt onset and termination: What is the mechanism?

\author{
1
}

Mukund A Prabhu ${ }^{1,2}$ MD DM PDF, Robert D. Anderson ${ }^{1}$ MBBS, Paul B Sparks MBBS, FRACP, Ph.D.

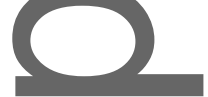

1.Department of Cardiology, Royal Melbourne Hospital and University of Melbourne Grattan Street, Parkville, Vic 3050, Australia

2. Kasturba Medical College, Manipal academy of higher education (Manipal University), Manipal,

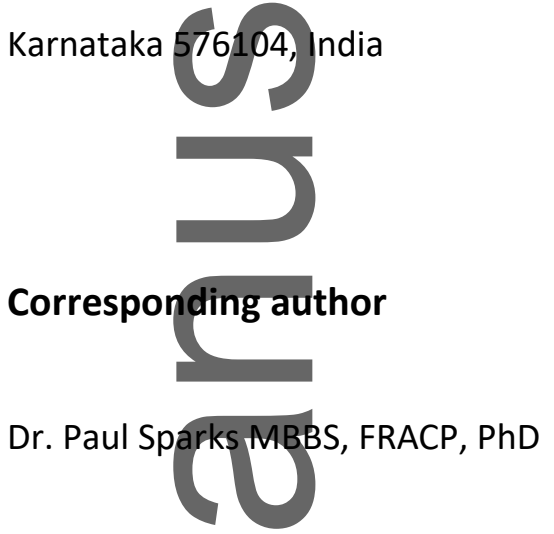

Director of Heart Rhythm Services, Royal Melbourne Hospital

Postal Address:

Department of Cardiology

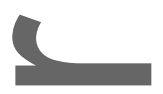

Royal Melbourne Hospital, 300 Grattan Street

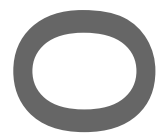

Parkville VIC 3050

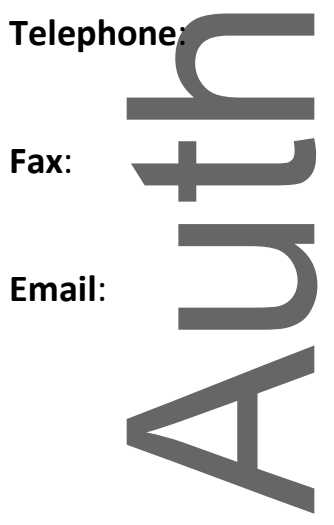

61409951330

61393495411

paul.sparks@mh.org.au

This is the author manuscript accepted for publication and has undergone full peer review but has not been through the copyediting, typesetting, pagination and proofreading process, which may lead to differences between this version and the Version of Record. Please cite this article as doi:

\subsection{1/jce.13672.}

This article is protected by copyright. All rights reserved. 
M.A.P has received the APHRS-Medtronic fellowship grant from the Asia Pacific Heart Rhythm Society. R.A is supported by postgraduate scholarships co-funded by National Health and Medical Research Council (NHMRC) and Royal Australasian College of Physicians NHMRC Woolcock Scholarships. P.S. has no conflicts of interests to declare.

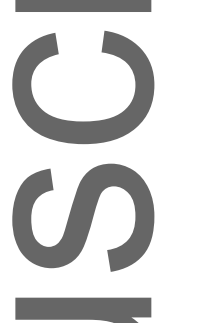

Keywords: atrioventricular nodal reentrant tachycardia, junctional tachycardia, supraventricular tachycardia
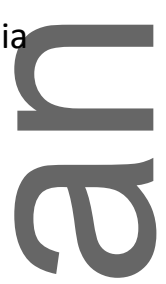

Case report

A 44-year old woman had undergone a slow pathway ablation for atrioventricular reentrant tachycardia in 2016. She had symptomatic relief for about a year. However, she had recurrence of palpitation recently, and she could distinguish that the episodes were slower and shortercompared to her original ones. Her arrhythmia was captured on a Holter tracing (Fig:1) and she underwent an electrophysiological study (Fig:2 \&3). The baseline intervals were normal, and there was retrograde dual AV nodal physiology with VA (retrograde H was not seen to measure HA) jump and echo for a 40ms window of S2. There was no antegrade dual AV rodal physiology (even with high dose of Isoprenaline), and the AV block CL was $470 \mathrm{~ms}$. The tachycardia was induced with difficulty by atrial burst pacing at $340 \mathrm{~ms}$ while on Isoprenaline at $8 \mathrm{mcg} / \mathrm{min}$ infusion. The tachycardia was of abrupt onset, with CL of $420 \mathrm{~ms}$, 
earliest A in the coronary sinus proximal (CSP) electrode, and a ventriculoatrial (VA) interval of 0ms. The entrainment showed a VAHV response with a long post-pacing interval (PPItachycardia $C L=140 \mathrm{~ms}$ ), and the difference between Stim-A and the VA intervals was $110 \mathrm{~s}$. The effect of atriat eetopics during the tachycardia is shown in Fig:2 and 3, recorded during the electrophysiological study (EPS). What is the likely mechanism of the tachycardia, and did the atrial ectopics reset the tachycardia?

\section{Discussion}

The Holter strip (Fig:1) shows the onset of the tachycardia, which is abrupt. More strikingly, the onset is with a QRS complex, and the RP interval was very short with the P wave immediately following the QRS. This suggests the possibility of an atrioventricular nodal reentrant taehycardia (AVNRT) being triggered by a 1:2 response, or a Junctional tachycardia (JT). The cycle length (CL) of the tachycardia was stable, and it terminated ( abruptly but with a change in the $\mathrm{P}$ wave axis and the RP relation The abruptness of the onset and the stability in the CL suggests the possibility of an AVNRT, as these are the features of a reentrant-mechanism. However, the termination of the tachycardia shows a striking change in the $\mathrm{P}$ waye axis, which progressively becomes isoelectric before getting upright and marching out of the QRS, and preceding it. Presumably, the sinus node must have accelerated and overdriven the tachycardia as seen in the latter part of the strip that shows sinus tachycardia. Such a response suggests an isoarrhythmic atrioventricular (AV) dissociation. Though an AV dissociation is possible in AVNRT, it is more commonly a feature of JT.

The atrial extrastimulus did not advance the His though it occurred before the His deflection (Fig:2). However, there was a spontaneous premature atrial complex (PAC) following this that nullifies the intended maneuver. But, the PAC did advance the His potential. The returning cycle commenced with a His potential with a fully compensatory 
pause. This continuation of the tachycardia is against a typical AVNRT, which would have terminated with advancement of the His. Moreover, the VA is not 'linked" in the few cycles T

after the PAC and this is also more consistent with JT. The fully compensatory pause speaks against the rare possibility of a re-initiation by $1: 2$ response through a slow pathway that would arguably be have a different returning cycle. Both the ectopics probably did not reset the tachycardia, resulting in a fully compensatory pause $\left(\mathrm{HH}^{\prime}+\mathrm{HH}=2 \mathrm{HH}\right.$, Fig:2). The compensatory pause (i.e. no reset) would also suggest a relatively protected $\mathrm{H}$ focus.

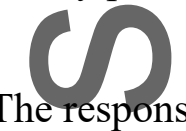

The response to atrial extra is useful in differentiating JT and AVNRT(1). The early atrial extras the advancement of His will engage the fast pathway orthodromically and thus terminate the AVNRT, whereas JT can continue with advancement, delay, or no change in the next beat. In contrast, the His-committed atrial extra doesn't affect JT, whereas it can advance or delay the next beat in AVNRT as it can engage the slow pathway that may conduct with or without a decrement. The His-committed atrial extra did not affect the tachycardia in the present case (Fig:3), whereas as early atrial ectopic, it advanced the His without terminating it. This latter response excludes a typical AVNRT that will be terminated by an atriat extra that advances the His, since this will render the fast pathway refractory. The His-committed APC should be interpreted with caution as an atrial extrastimulus can penetrate into the tachycardia focus without affecting the timing of the His. The refractoriness of His at the time of atrial extra can only be assured by ensuring that the local $\mathrm{A}$ in the His catheter follows the His potential(1). This is important because the atrial extra penetrating the tachycardia focus can evoke any of the responses- advancement, delay or lack of any affect in the case of JT. In the present case it is likely that though the local His was recorded after the His potential, the tachycardia was not reset as revealed by the unperturbed HH interval despite the shortened $\mathrm{AA}^{\prime}$ interval and the fully compensatory pause $\left(\mathrm{AA}^{\prime}+\mathrm{AA}=2 \times \mathrm{AA}\right.$, Fig) 
There are a few maneuvers to differentiate between AVNRT and JT (2) (3), which are summarized in tabe:1. The patient was planned for medical management in view of difficulty in induction, and higher risk of AV block associated with the ablation of JT.
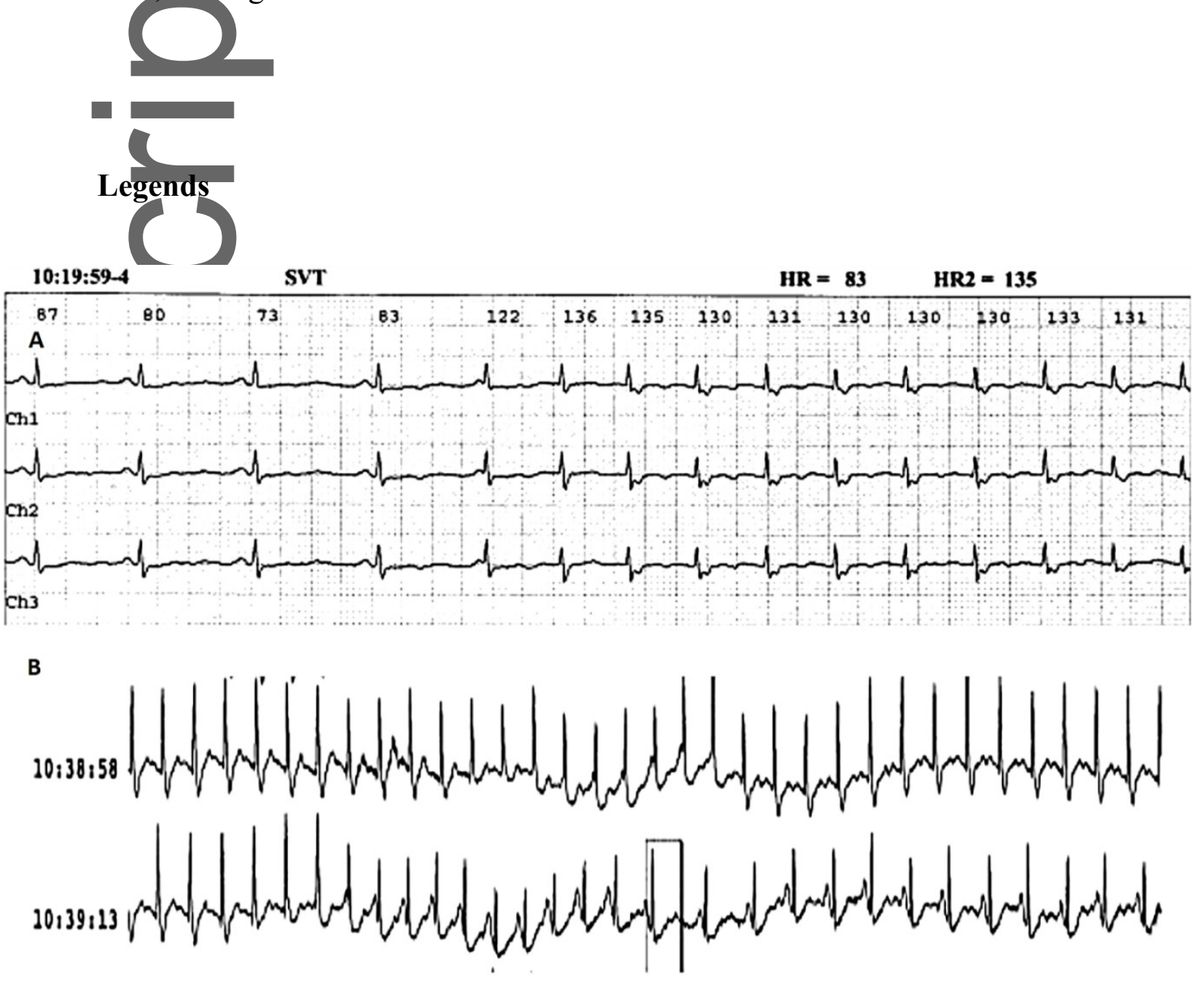

Figure:1A The Holter tracing shows the onset of the tachycardia with a QRS complex ( $5^{\text {th }}$ complex $)$ that is coincident on the $\mathrm{P}$ wave. The first 2 beats of the tachycardia lack as P wave after the QRS, whereas the subsequent beats have a P wave immediately following the QRS. Panel B shows the termination of the tachycardia as recorded by the channel-1 of the Holter. The $\mathrm{P}$ wave axis changes to isoelectric, and then to positive. The RP relation alters as the $\mathrm{P}$ wave that followed the QRS disappears inside the $\mathrm{QRS}$ before marching out to precede it suggesting an isoarrhythmic AV dissociation. Ch1-3 represents the three Holter channels 


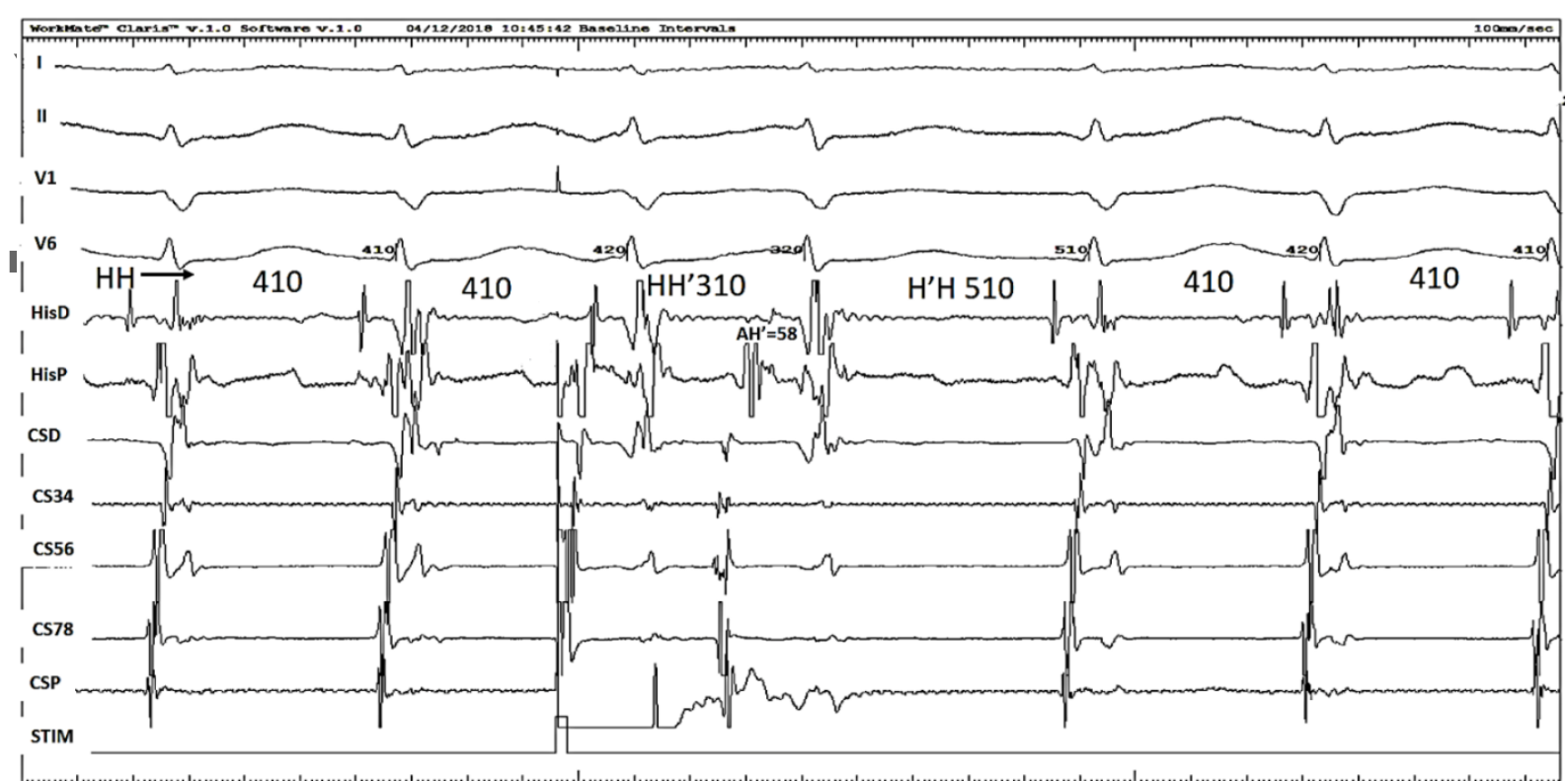

Figure:2 The EPS tracing at $100 \mathrm{~mm} / \mathrm{sec}$ paper speed. The channels represent (from top to bottom), the standard electrocardiographic leads I, II, V1, V6, followed by the His distal andproximal electrodes (HisD and HisP, respectively), followed by coronary sinus electrodes presented in distal to proximal order (CSD to CSP, respectively) in this as well as the next figure.

The HH intervals are shown in bold. The atrial extrastimulus which did not advance the $\mathrm{H}$. This is followed by a spontaneous atrial ectopic. The resultant His (H') is advanced by $100 \mathrm{~ms}$. The subsequent pause is fully compensatory $\left(\mathrm{HH}^{\prime}+\mathrm{H}^{\prime} \mathrm{H}=410+510=2 \mathrm{xHH}=820\right.$ ). The tachycardia continues at the initial rate thereafter. The intervals are in milliseconds.

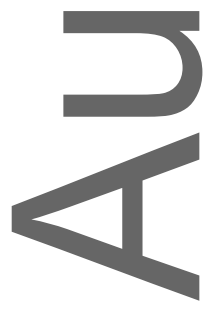




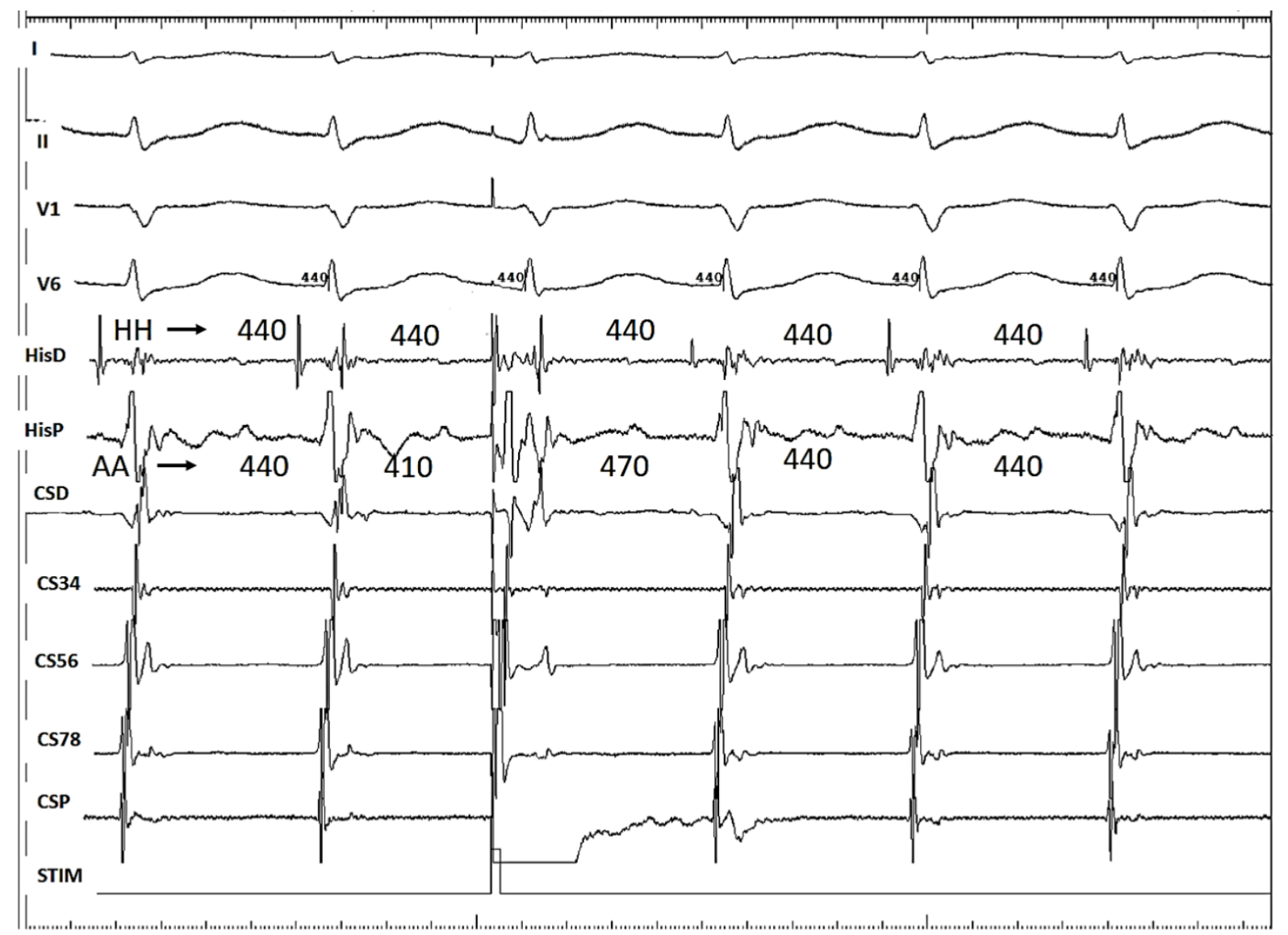

Figure:3 The HH intervals and the AA intervals are depicted in bold. The atrial extrastimulus is committed to the His. Note that the local A recorded in the His occurs after the His. The HH interval is unperturbed, whereas the AA is shortened to $410 \mathrm{~ms}$. The subsequent pause is $470 \mathrm{~ms}$ and is fulty compensatory $(410+470=2 \mathrm{x} 410=880 \mathrm{~ms})$. Note the that the tachycardia is slightly slower in the current tracing, likely due to the effect of sedation.

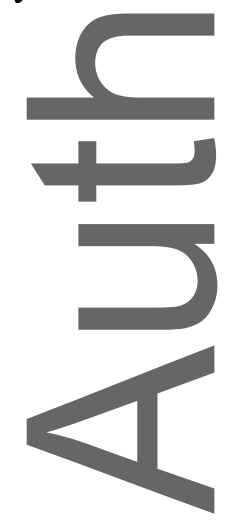




\section{References}

1. Padanilam BJ, Manfredi JA, Steinberg LA, Olson JA, Fogel RI, Prystowsky EN.

Differentiating Junctional Tachycardia and Atrioventricular Node Re-Entry<smiles>C1CC2CCCC2C1</smiles>

Tachycardia Based on Response to Atrial Extrastimulus Pacing. J Am Coll Cardiol

[Internet]. Elsevier Masson SAS; 2008;52(21):1711-7. Available from:

http://dx.doi.org/10.1016/j.jacc.2008.08.030

2. Fan R, Tardos JG, Almasry I, Barbera S, Rashba EJ, Iwai S. Novel use of atrial overdrive pacing to rapidly differentiate junctional tachycardia from atrioventricular nodal reentrant tachycardia. Hear Rhythm [Internet]. Elsevier Inc.; 2011;8(6):840-4. Available from: http://dx.doi.org/10.1016/j.hrthm.2011.01.011

3. Srivathsan K, Gami AS, Barrett R, Monahan K, Packer DL, Asirvatham SJ.

Differentiating atrioventricular nodal reentrant tachycardia from junctional tachycardia: Novel application of the delta H-A interval. J Cardiovasc Electrophysiol.

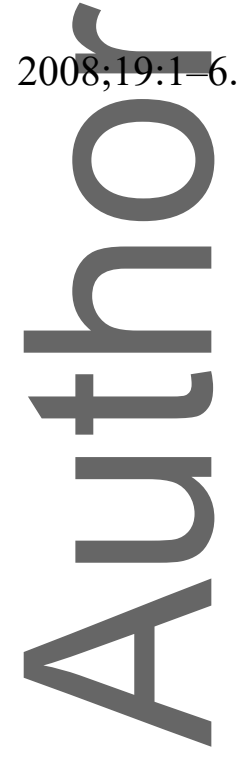


Table:1 Summarizes the various maneuvers that help to differentiate AVNRT and JT and the precautions to interpretation.

Abbreviations- AVNRT-Atrioventricular nodal reentrant tachycardia. FP- Fast pathway, JTJunctional tachycardia,

\begin{tabular}{|c|c|c|c|}
\hline Manoey & AVNRT & JT & Comment \\
\hline $\begin{array}{l}\text { Early Atrial } \\
\text { extra }\end{array}$ & $\begin{array}{l}\text { Resets the } \\
\text { tachycardia } \\
\text { (advancement } \\
\text { of His with } \\
\text { continuation of } \\
\text { tachycardia) }\end{array}$ & $\begin{array}{l}\text { Advance the } \\
\text { His and } \\
\text { terminates the } \\
\text { tachycardia }{ }^{2} \text {, or } \\
\text { Resets it with a } \\
\text { prolonged AH } \\
\text { interval (delays } \\
\text { the } \mathrm{H})^{2}\end{array}$ & $\begin{array}{l}1 \text { Specific for JT } \\
\text { with the } \\
\text { exception } \\
\text { being double } \\
\text { fire } \\
2 \text { Nonspecific } \\
\text { responses as } \\
\text { the may occur } \\
\text { in JT as well }\end{array}$ \\
\hline $\begin{array}{l}\text { His refracto } \\
\text { Atrial extra }\end{array}$ & $\begin{array}{l}\text { Doesn't affect } \\
\text { the } \\
\text { tachycardia }^{3}\end{array}$ & $\begin{array}{l}\text { Can advance, } \\
\text { delay or } \\
\text { terminate the } \\
\text { tachycardia }^{4}\end{array}$ & $\begin{array}{l}3 \text { Nonspecific } \\
\text { response } \\
4 \text { Specific for } \\
\text { AVNRT }\end{array}$ \\
\hline $\begin{array}{l}\text { V pacing at } \\
\text { TCL- Delta HA } \\
\text { interval }\end{array}$ & $\begin{array}{l}\text { Close to } 0 \text { (or } \\
\text { positive) }\end{array}$ & Negative & $\begin{array}{l}\text { Serial HA } \\
\text { activation in JT } \\
\text { as opposed to } \\
\text { parallel } \\
\text { activation in }\end{array}$ \\
\hline
\end{tabular}




\begin{tabular}{|c|c|c|c|}
\hline & & & $\begin{array}{l}\text { AVNRT } \\
\text { HA interval in } \\
\text { AVNRT is a } \\
\text { pseudo interval }\end{array}$ \\
\hline $\begin{array}{l}\text { Atrial } \\
\text { entrainment- } \\
\text { returning cycle }\end{array}$ & AHHA response & AHA response & $\begin{array}{l}\text { Double fire is a } \\
\text { potential } \\
\text { exception } \\
\text { (AVNRT mimics } \\
\text { JT) } \\
\text { Diseased FP } \\
\text { with bystander } \\
\text { dual AVN-JT } \\
\text { may potentially } \\
\text { mimic AVNRT }\end{array}$ \\
\hline
\end{tabular}

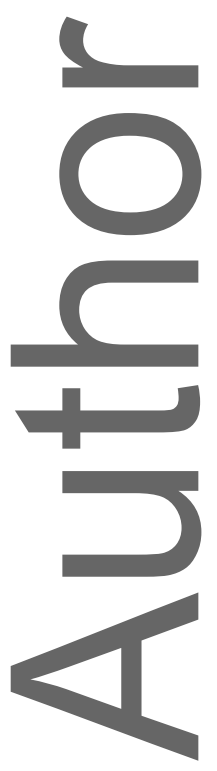




\section{University Library}

\section{- M M N E R VA A gateway to Melbourne's research publications}

Minerva Access is the Institutional Repository of The University of Melbourne

Author/s:

Prabhu, MA;Anderson, RD;Sparks, PB

Title:

Supraventricular tachycardia with abrupt onset and termination: What is the mechanism?

Date:

2018-11-01

Citation:

Prabhu, M. A., Anderson, R. D. \& Sparks, P. B. (2018). Supraventricular tachycardia with abrupt onset and termination: What is the mechanism?. JOURNAL OF CARDIOVASCULAR ELECTROPHYSIOLOGY, 29 (11), pp.1584-1587. https://doi.org/10.1111/jce.13672.

Persistent Link:

http://hdl.handle.net/11343/284325 